\title{
Study of board bending degree on hydrodynamic performances of a single-layer cambered otter-board
}

\author{
Lei WANG ${ }^{1,2}$, Lu Min WANG ${ }^{1}$, Yong Li LIU1 ${ }^{1}$, Wen Wen YU ${ }^{1}$, Guang Rui QI ${ }^{1}$, Yong Jin WANG ${ }^{1}$, Xun ZHANG ${ }^{1, *}$, and \\ Rong Jun $\mathrm{ZHANG}^{3}$ \\ ${ }^{1}$ Key Laboratory of Oceanic and Polar Fisheries, Ministry of Agriculture; East China Sea Fisheries Research Institute, Chinese Academy \\ of Fishery Sciences, Shanghai 200090, China \\ ${ }^{2}$ College of Marine Sciences, Shanghai Ocean University, Shanghai 201306, China \\ ${ }^{3}$ China National Fisheries Corporation, Beijing 100032, China
}

\begin{abstract}
The effect of board bending degree on hydrodynamic performances of a single-layer cambered otter-board was investigated using engineering models in a wind tunnel. Three different bending degree boards were evaluated at a wind speed of $28 \mathrm{~m} / \mathrm{s}$. Parameters measured included: drag coefficient $\mathrm{C}_{\mathrm{x}}$, lift coefficient $C_{y}$, pitch moment coefficient $C_{m}$, center of pressure coefficient $C_{p}$, over a range of angle of attack $\left(0^{\circ}\right.$ to $\left.70^{\circ}\right)$. These coefficients were used in analyzing the differences in the performance among the three otter-board models. Results showed that the bending of the board(No. 2, No. 3) increased the water resistance of the otter-board, and improved the lift coefficient of the otter-board in the small angle of attack $\left(0^{\circ}<\alpha \leq 20^{\circ}\right)$; the maximum lift coefficients $C_{y}$ of otter-board model (No. 1) was higher (1.680, $\left.\alpha=25^{\circ}\right)$. the maximum lift - drag ratios of models (No. 1, No. 2 and No. 3) are $6.822\left(\alpha=7.5^{\circ}\right), 6.533(\alpha=$ $\left.2.5^{\circ}\right)$ and $6.384\left(\alpha=5.0^{\circ}\right)$, which showed that the board bending reduces the lift-to-drag ratio of the otter-board.The stability of the No. 3 model was better than those two models (No. 1, No. 2) in most range of attack angle, but No. 1 otter-board model had a better stability in roll of otter-board. The findings of this study can offer useful reference data for the structural optimization of otter-boards for trawling.
\end{abstract}

\section{Introduction}

The merits of the hydrodynamic performance of otterboard what is the important part of fishing gear for spreading the trawl mouth can be measured on the basis of the lift coefficient of the otter-board, the drag coefficient of the otter-board, the pitching moment coefficient, and the center of pressure coefficient of the otter-board [1]. Optimizing the structure of otter-boards may improve the hydrodynamic performance of the otter-board [2-13]. Improvements in the hydrodynamic performance of otter-boards has become a major research interest as the development of offshore trawler fleets increasing globally in recent decades. The following study investigates the importance of the board bending degree within the otter-board. We describe an experiment using otter-board models $(\mathrm{n}=3$ designs $)$ in a wind tunnel in which we measured various hydrodynamic coefficients for a range of angles of attack. The results are relevant as a reference for the study of the structural parameters of the board bending degree of otter-boards.

\section{Material and Methods}

\subsection{Design and manufacture of otter-board model}

The otter-boards evaluated in this study were singlelayer curved structures with differrent board bending degree (figure 1), which was achieved by a folded joint of several boards. This structure design was simplified in order to meet objectives and requirements of the study. 


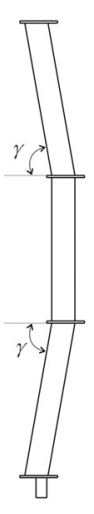

Side view

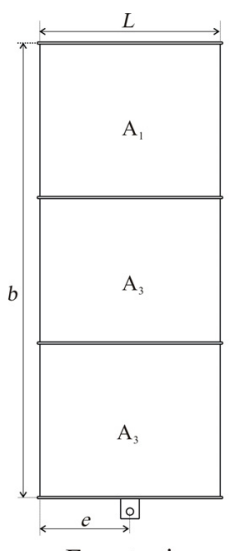

Front view

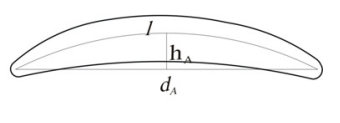

Top view
Fig. 1. Structure and parameters of otter-board

Note: L: chord; b: span; e: distance between fulcrum and the front end of model; $A_{1-n}$ : main-panel; $\gamma$ : bending angle of board; 1: arc length of main-panel; $h_{\mathrm{A}}$ : distance from the vertex of the arc to the arc chord; $d_{A}$ : length of arc chord.

Each of models had an aspect ratio of 2.5, and were identical in many structural parameters and dimensions (table 1). The curvature of the main-panel was $0.12\left(\delta_{A}\right)$ and was consistent in all models. The parameters that varied between the models was the number of boards $\left(\mathrm{A}_{1}\right.$ n) and the bending angle between boards. The models were made of steel with painted surfaces (figure 2).

Table 1. Descriptive characteristics of the three model otter boards evaluated in this study.

\begin{tabular}{|c|c|c|c|}
\hline No. & $\mathbf{1}$ & $\mathbf{2}$ & $\mathbf{3}$ \\
\hline $\boldsymbol{L} / \mathbf{m}$ & 0.249 & 0.258 & 0.258 \\
\hline $\boldsymbol{b} / \mathbf{m}$ & 0.628 & 0.637 & 0.643 \\
\hline $\boldsymbol{\lambda}$ & 2.5 & 2.5 & 2.5 \\
\hline $\boldsymbol{S} / \mathbf{m}^{\mathbf{2}}$ & 0.156 & 0.164 & 0.166 \\
\hline $\boldsymbol{e} / \mathbf{m}$ & 0.140 & 0.129 & 0.129 \\
\hline $\boldsymbol{\gamma}$ & - & $80^{\circ}$ & $80^{\circ}$ \\
\hline $\boldsymbol{l}$ & 0.260 & 0.260 & 0.260 \\
\hline $\boldsymbol{\delta}_{\boldsymbol{A}}$ & 0.12 & 0.12 & 0.12 \\
\hline
\end{tabular}

Note: $L$ : chord; $b$ : span; $\lambda(b / L)$ : aspect ratio; $S(L \cdot b)$ : surface area; $e$ : distance between fulcrum and the front end of model; $\gamma$ : bending angle of board; $l$ : arc length of main-panel; $\delta_{A}\left(h_{A}\right)$ $\left.d_{A}\right)$ : curvature of main-panel.
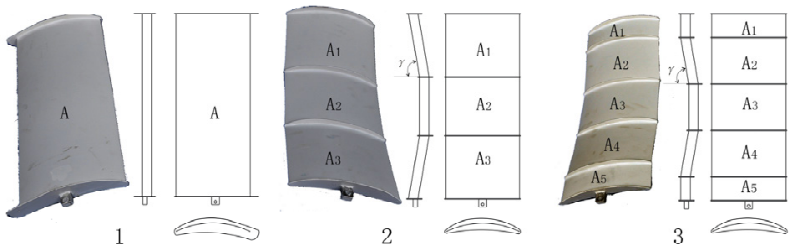

Fig. 2. Three otter-board models evaluated in this study.

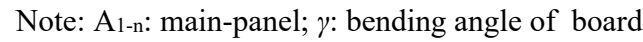

\subsection{Test facility}

The wind tunnel used for this experiment was the $\mathrm{NH}-2$ wind tunnel located at Nanjing University of Aeronautics and Astronautics, China. The tunnel is a closed reflux wind tunnel with a double-string test section. The experiment was conducted in a small test section. Dimensions of the test section were $6 \mathrm{~m}$ (length) $\times 3 \mathrm{~m}$ (width) $\times 2.5 \mathrm{~m}$ (height). The cross-sectional area was $7.18 \mathrm{~m}^{2}$. The minimum and maximum wind speeds of the tunnel were $5 \mathrm{~m} / \mathrm{s}$ and $90 \mathrm{~m} / \mathrm{s}$, respectively. Figure 3 illustrates the experimental setup inside the wind tunnel. The otter-board models were attached to a dynamometer compromising a six-component mechanical tower-balance to measure forces in all directions. The data acquisition and processing system used is composed of a pre -amplifier and a four networked computer system.

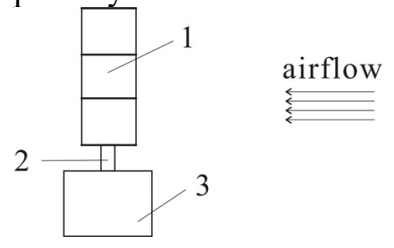

Fig. 3. Installation instruction of otter-board model in wind tunnel.

Note: 1.otter-board model 2.model connection 3.six-component force balance

\subsection{Test method}

\subsubsection{Parameter definition of test model}

Test model need to be installed on the wind tunnel in six-component balance mechanical base according to the order, angle of attack of model rotates by the $0^{\circ}-70^{\circ}$ when the wind speed reaches $28 \mathrm{~m} / \mathrm{s}$ (room temperature $20{ }^{\circ} \mathrm{C}$ ), wherein the angle of attack in the range $0^{\circ}-50^{\circ}$, $2.5^{\circ}$ intervals to record a measurement data point, after the attack angle $50^{\circ}$, each measurement interval of $5^{\circ}$ to record data points, there are 25 sets of data totally, including the drag coefficient $C_{x}$, the lift coefficient $C_{y}$, the pitch moment coefficient $C_{\mathrm{m}}$ and the center of pressure coefficient $C_{\mathrm{p}}$.

The relevant parameters of models in the wind tunnel test section are defined as shown in figure 4. In figure 4, $\mathrm{O}$ is torque reference point, which is the punch of the model at the bottom. During the test, the resistance of the model is provided by the force of balance along the $\mathrm{X}$ axis direction, the lift is provided by the force of balance along the $\mathrm{Z}$-axis direction, and the pitch moment is provided by the $M_{\mathrm{y}}$ of balance along the $\mathrm{Z}$-axis direction.

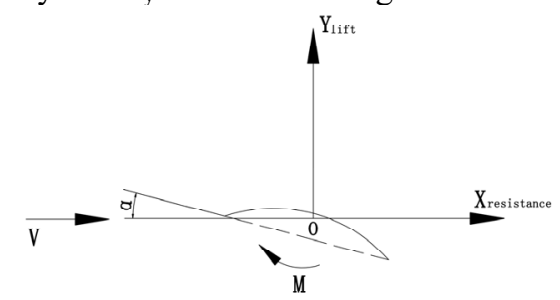

Fig. 4. Parameter definition diagram of test model in wind tunnel.

For this test, Wind speed $V=28 \mathrm{~m} / \mathrm{s}$, when the Reynolds number $R_{e}=V L / v=0.93 \times 10^{6}$ (coefficient of viscosity $v=15 \times 10^{6} \mathrm{~m}^{2} \cdot \mathrm{s}^{-1}$ ) [14]. 


\subsubsection{Parameter definition of test measurement}

Three components: lift $Y$, drag $X$, pitching moment $M$ (around the fulcrum), while the distance from the center of pressure to the front-end otter-board $d=e-(M / N)$ [15], ( $N$ is the normal force).

Lift coefficient $\quad C_{y}=\frac{Y}{\rho V^{2} S / 2} \quad[3] ; \quad$ drag coefficient $\quad C_{x}=\frac{X}{\rho V^{2} S / 2} \quad ; \quad$ pitch moment coefficient $\quad C_{m}=\frac{M}{\rho V^{2} S L / 2} \quad ; \quad$ center of pressure coefficient ${ }_{C_{p}}=\frac{d}{L}$.

Air density $\rho=1.225 \mathrm{~kg} / \mathrm{m}^{3}$ in above formula; $S$ is otter-board area $\left(\mathrm{m}^{2}\right) ; L$ is the otter-board chord length (m).

All the experimental data have been carried out the stent disturbance correction which is completed by the method of taking out light pole directly.

\section{Results and Discussion}

\subsection{Drag coefficient and lift coefficient}

Data from the experiment included the drag coefficient $C_{x}$, the lift coefficient $C_{y}$, the pitch moment coefficient $C_{\mathrm{m}}$, and the center of pressure coefficient $C_{p}$. The liftdrag ratio was computed $\left(C_{y} / C_{x}\right)$, which is an important factor for determining the merits of the hydrodynamic performance of otter-boards. An otter-board with excellent hydrodynamic properties can achieve higher lift-drag ratio and improved stability; such performance can be analyzed by comparing the pitching moment coefficient $C_{\mathrm{m}}$ and the center of pressure coefficient $C_{p}$. The test data were divided into groups, yielding $C_{x^{-}} \alpha$, and $C_{y}-\alpha$ graphs shown in figure 5. These graphs are used for analyzing the differences in the hydrodynamic properties of the three otter-board models.
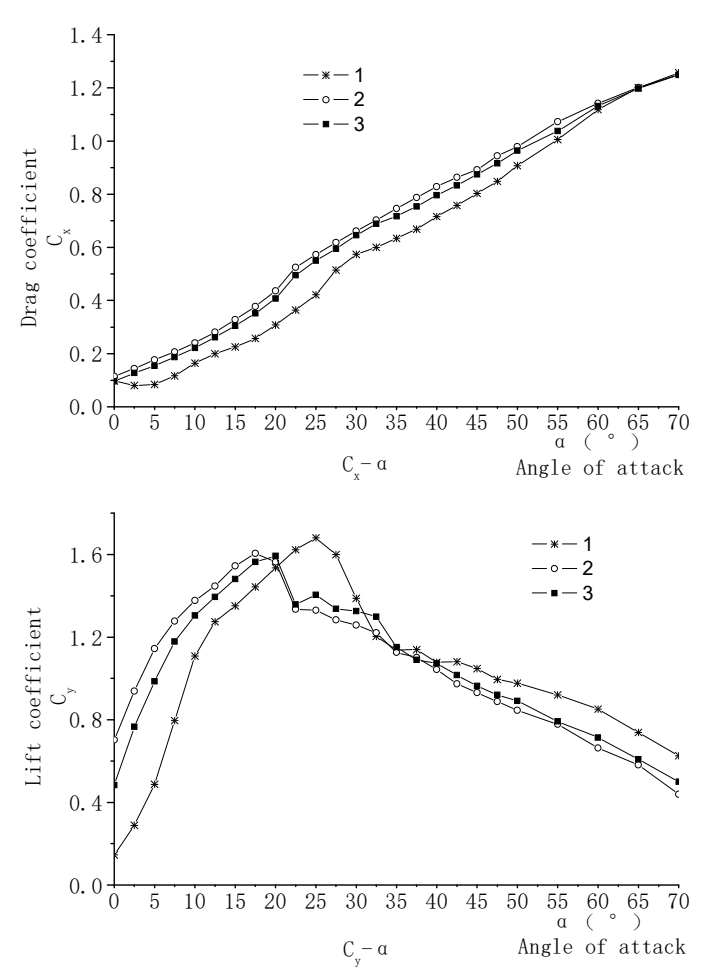

Fig. 5. Drag coefficient and lift coefficient of three otter-board models across a range of angle of attack.

In figure 5, $C_{x}-\alpha$ and $C_{y}-\alpha$ graphs show the variation curve of the drag and lift coefficient of the three models while the angle of attack $\alpha$ changes. Compared to a nonangular otter-board(No. 1), the bending of the board(No. 2 , No. 3) increases the water resistance of the otter-board. However, in the small angle of attack $\left(0^{\circ}<\alpha \leq 20^{\circ}\right)$, the board bending can increase the lift coefficient of the otter-board. The maximum lift coefficients $C_{y}$ of No. 1 otter-board model is higher $\left(1.680, \alpha=25^{\circ}\right)$.

\subsection{Lift-drag ratio}

In figure 6 , the maximum lift-drag ratios of No. 1 , No. 2 and No. 3 models are $6.822\left(\alpha=7.5^{\circ}\right), 6.533\left(\alpha=2.5^{\circ}\right)$ and $6.384\left(\alpha=5.0^{\circ}\right)$, respectively. It can be seen that the board bending reduces the lift-to-drag ratio of the otterboard, although it has a relatively high lift-to-drag ratio in the small angle of attack.

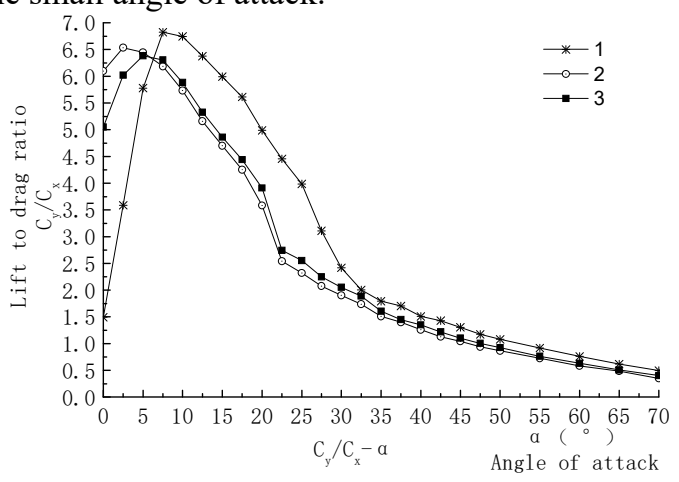

Fig. 6. Lift-drag ratio of three otter-board models across a range of angle of attack. 


\subsection{Stability of otter-board}

Pitching moment can be divided into upper and lower pitching moments, which are usually distinguished by positive and negative values, Positive means the otterboard tilts backward, and negative means tilts forward. Its absolute value represents the level of pitching moment; and the pitching moment coefficient $C_{\mathrm{m}}$ tending to 0 represents the more excellent stability of otter-board.

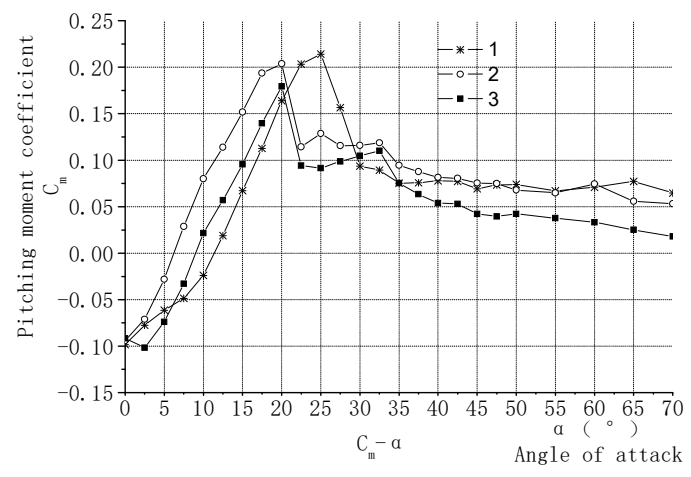

Fig. 7. Pitching moment coefficient of three otter-board models across a range of angle of attack.

With the change of the angle of attack, the $C_{\mathrm{m}}$ of the three models are different. As figure 7 illustrated, the stability of the No. 3 model is better than that of the No. 2 model $\left(10^{\circ} \leq \alpha<70^{\circ}\right)$, and the best in the 3 models $\left(35^{\circ} \leq \alpha<70^{\circ}\right)$.

Table 2. Parameters of three otter-board models for $C_{p}$ analysis.

\begin{tabular}{|c|c|c|}
\hline No. & $\begin{array}{c}\text { Angle corresponding to the } \\
\text { maximum lift -drag ratio } \\
\boldsymbol{\alpha}\end{array}$ & $\begin{array}{c}\text { Variable } \\
\text { coefficient of } \\
\boldsymbol{C}_{\mathbf{p}}\end{array}$ \\
\hline 1 & $7.5^{\circ}$ & $8.3 \%$ \\
\hline 2 & $2.5^{\circ}$ & $9.5 \%$ \\
\hline 3 & $5.0^{\circ}$ & $9.0 \%$ \\
\hline
\end{tabular}

The stability in roll of otter-board can be measured according to the center of pressure coefficient $C_{\mathrm{p}}$; and the way of comparison is analyzing the coefficient of variation in $C_{\mathrm{p}}$ within the range of angle approximately $5^{\circ}$ of the angle of attack corresponding to the maximum lift-drag ratio; a smaller coefficient results in the improved stability [16-17]. The calculated data are shown in table 2 . The minimum variation coefficient of $C_{\mathrm{p}}$ is $8.3 \%$; this value also means that the stability of No. 1 otter-board model is better in roll of otter-board.

\section{Conclusion}

Test analysis shows that the board bending degree has a point for equilibrating the hydrodynamic performances of otter-board. No.2 and No.3 otter-boards with the bending board have the higher lift coefficient at the angle of attack $\left(0^{\circ}<\alpha \leq 20^{\circ}\right)$, and No. 1 otter-board model has the higher maximum lift coefficients $(1.680, \alpha$ $=25^{\circ}$ ). Stability analyzing by the data of $C_{m}$ and $C_{p}$, the board bending will improve the pichting stability of the otter-board during certain attack angle, and the stability of No.1 otter-board model in roll is better. The data and conclusions of this study can provide a reference for the design of otter-board.

This work is financially supported by the National Marine Economic Innovation and Development Demonstration Project in Pudong New Area, Shanghai (No. PD-HY-006).

\section{References}

1. G. X. Guo, T. Y. Liu, X. H. Huang, F. L. Gu. Theory and Practice of trawl doors Kinetic. Guang. Sci. \& Tech. Pub. (2008)

2. Y. Q. Zhou. Mechanics of fishing gear. Chi. Agr. Pub. (2001)

3. X. Z. Chen, X. C. Huang. Theory and method of gear model test. Sh. Sci. \& Tech. Pub. (2011)

4. Y. Takahashi, Y. Fujimori, F. X. Hu, X. L. Shen, N. Kimura. Fis. Res. 400, 161(2015)

5. M. K. Broadhurst, D. J. Sterling, R. B. Millar. Fis. Man. \& Eco. 407, 22(2015)

6. K. Fukuda, F. X. Hu, T. Tokai, K. Matuda. Ni. Su. Gak. 97, 66(2000)

7. C. D. Park, K. Matuda, F. X. Hu. Ni. Su. Gak. 920, 62(1996)

8. X. L. Shen, F. X. Hu, T. Kumazawa, D. Shiode, T. Tokai. Fis. Sci. 433, 81(2015)

9. L. Wang, L. M. Wang, C. L. Feng, A. Z. Zhou, W. W. Yu, Y. Zhang, X. Zhang. Aqu. \& Fis. 234, 2(2017)

10. L. Wang, L. M. Wang, J. G. Shi, Y. Zhang, Y. L. Liu, W. W. Yu, X. Zhang. MAT. W. Con. 5004, 128(2017)

11. L. Wang, L. M. Wang, A. Z. Zhou, J. G. Shi, Y. Zhang, G. D. Xu, X. Zhang. MAT. W. Con. 5003, 128(2017)

12. L. Wang, L. M. Wang, C. L. Feng, X. Zhang, A. Z. Zhou, Y. Zhang, Y. L. Liu, G. R. Qi. Mar. Fis. 682, 39(2017)

13. X. Zhang, J. H. Wang, M. Y. Wang, Y. F. Yu, B. S. Xu. Jou. Fis. Sci. Ch. 5, 11(2004)

14. J. H. Wang, M. Y. Wang, X. Zhang, Y. F. Yu, B. S. Xu. Jou. Fis. Sci. Ch. 9, S1(2004)

15. M. Y. Wang, J. H. Wang, X. Zhang, Y. F. Yu, B. S. Xu. Jou. Fis. Ch. 311, 3(2004)

16. L. Yang. Fis. Sci. Tec. 38, 2(1996)

17. L. Yang. Fis. Sci. Tec. 42, 5(1996) 